\title{
Mercedes Rein y su obra de traductora. Aproximación a una antología de traducción inédita'
}

\author{
Leticia Hornos-Weisz \\ letihornos@gmail.com \\ https://orcid.org/0000-0001-8329-0477 \\ Centro de Lenguas Extranjeras, Facultad de Humanidades y Ciencias de la \\ Educación, Universidad de la República, Uruguay
}

\begin{abstract}
Resumen
El presente trabajo aborda la obra de traductora de la uruguaya Mercedes Rein (1931-2006) a través de una lectura que jerarquiza el relieve temporal de su figura (Delisle, 2018) y la arista histórica de la mediación traductiva. En primer lugar, el artículo se concentra en su intervención intelectual como integrante de la generación de la crisis (Rama, 1972) y el diálogo que su obra entabla con las prácticas instauradas por otros agentes culturales del campo vernáculo. Sobre esta base se prioriza el análisis del proceso de gestación de una antología de traducción (Frank, 2001) de poesía en lengua alemana, compilada por Rein al inicio de su trayectoria. Por tratarse de material inédito y sin catalogar, se describen las principales oscilaciones cronológicas identificadas en la dinámica de los borradores, así como otras particularidades del aparato paratextual. Por último, el artículo no puede soslayar una serie de colaboraciones críticas que Rein publica en el semanario Marcha y que representan, hasta el momento, el único acceso édito a la antología. El espacio de enunciación configurado por esas reseñas pone en diálogo la práctica traductora con la crítica literaria y los procesos de recepción de la poesía en lengua alemana, al tiempo que deja ver elementos específicos de la experiencia traductiva.
\end{abstract}

Palabras clave: Mercedes Rein, traducción de poesía alemana, antología de traducción, crítica literaria, campo cultural uruguayo.

\section{Mercedes Rein and her Translator Work. An Approach to an Unpublished} Anthology of Translation

\begin{abstract}
This study approaches the translator work done by Mercedes Rein (1931-2006) by emphasizing the temporal dimension of her figure (Delisle, 2018) and the historical perspective of her mediation in translation. Firstly, it focuses on the most meaningful aspects of her intellectual intervention as a member of the crisis generation (Rama, 1972), and on the dialogue between her work and the practices established by other vernacular cultural agents. Based on this, it prioritises analysing the gestation process of a translation
\end{abstract}

1 El presente artículo forma parte de mi tesis doctoral, en curso, sobre la obra de traductora de la escritora uruguaya Mercedes Rein, en el marco del Programa de Posgrado en Estudios de Traducción (PGET) de la Universidad Federal de Santa Catarina (UFSC), Brasil. 
anthology (Frank, 2001) of German poetry, compiled by Rein at the initial stages of her intellectual path. Since the approach used deals with unpublished and uncategorised material, this study describes the main chronological oscillations identified in the dynamics of drafts and variations on paratexts. Lastly, critic collaborations are mentioned, published by Rein in the weekly journal Marcha and taken from the unpublished anthology. These are, so far, the only published access to the anthology. The enunciation space built in those reviews enters into a dialogue between translation practice and literary criticism about the reception of German poetry, while revealing specific elements of the translation experience.

Keywords: Mercedes Rein, translation of German poetry, translation anthology, literary criticism, Uruguayan cultural field.

\section{Mercedes Rein et son travail de traductrice. Une approche d'une anthologie} de traduction inédite

\section{Résumé}

Cet article porte sur le travail de traductrice de l'Uruguayenne Mercedes Rein (1931-2006) à travers une lecture qui met en avant la dimension temporelle de sa figure (Delisle, 2018) et la perspective historique de sa médiation en traduction. Tout d'abord, il se concentre sur son intervention intellectuelle en tant que membre de la génération de la crise (Rama, 1972) et sur le dialogue entre son travail et les pratiques établies par d'autres acteurs culturels du domaine vernaculaire. Dans ce contexte, l'analyse du processus de gestation d'une anthologie de traduction (Frank, 2001) de poésie en langue allemande est priorisée, compilée par Rein aux premiers stades de son parcours. Étant donné qu'il s'agit de matériel inédit et non classé, cet article décrit les principales oscillations chronologiques identifiées dans la dynamique des ébauches et des particularités du paratexte. Enfin, l'article ne peut ignorer une série de contributions critiques publiées par Rein dans l'hebdomadaire Marcha et qui représentent, jusqu'au présent, le seul accès publié à l'anthologie. L'espace d'énonciation façonné par ces aperçus met en dialogue la pratique de la traduction avec la critique littéraire et les processus de réception de la poésie en langue allemande, en même temps qu'il révèle des éléments spécifiques de l'expérience de traduction.

Mots clés : Mercedes Rein, traduction de poésie allemande, anthologie de traduction, critique littéraire, domaine culturel uruguayen. 


\section{Introducción}

En Retratos de traductores y traductoras, Jean Delisle (2018) redobla una de las premisas epistemológicas centrales de su investigación en el campo de la historia de la traducción: el relieve temporal de la figura del traductor. Para eso reivindica la pertinencia de la caracterización biográfica como un modo de acceder, interpretar y comprender los fenómenos traductivos en el seno de los sistemas literarios y evaluar, a la luz de un determinado conjunto de herramientas teóricas, su incidencia en el desarrollo intelectual de las comunidades culturales. En el marco de los estudios de traducción, este tipo de abordaje prioriza la función de los traductores como agentes mediadores y sujetos históricos responsables de una actividad textual creativa (Levý, 2011, pp. 57-58). Desde el punto de vista metodológico, el retrato permite articular los aspectos biográficos centrales del traductor con las coordenadas contextuales que circunscriben su proyecto. De acuerdo a Delisle:

El sujeto traduciente, así como el escritor, es portador de representaciones simbólicas de su sociedad. Por esto, el conocimiento de este sujeto es indispensable para la interpretación y la comprensión de las obras traducidas. [...] Elaborar el retrato de un traductor puede ser visto eventualmente como un modo de análisis, un modo de lectura: es la puesta en perspectiva de una "obra de traductor" (comparable a una "obra de escritor"), con el fin de conocerla mejor y de aclarar sus zonas oscuras (2018, p. 12).

Propongo así un acercamiento a la figura intelectual de Mercedes Rein (1931-2006) que intenta reconstruir el sustrato histórico y cultural desde el cual emerge su obra de traductora. En la primera parte, el artículo presta especial atención a aquellas características y transformaciones del campo intelectual uruguayo que circunscriben su trayecto traductivo en sus inicios, como docente y crítica literaria, hasta principios de la década del setenta, cuando ya es una escritora y traductora reconocida en la región. Con el fin de ilustrar el diálogo que establece su obra traductiva - pero también crítica y narrativa - con las prácticas instauradas por otros agentes de traducción, me apoyo en algunas de las reflexiones de Ángel Rama en torno a la generación crítica (1972) y en la investigación sobre publicaciones periódicas uruguayas dirigida por Pablo Rocca (2012).

De este recorrido, que intenta reivindicar el papel histórico del sujeto traduciente, emerge la singularidad de la labor de Rein. Sus traducciones de teatro en lengua alemana, fundamentalmente las de Bertolt Brecht, la convirtieron en una referencia dentro del movimiento de teatro independiente uruguayo de los años sesenta. En cambio, muy poco es lo que se conoce sobre su actividad traductiva y el vínculo con el ejercicio de otras prácticas al comienzo de su carrera profesional y artística. Por eso, en la segunda parte se busca recomponer la genealogía de un proyecto de traducción que hoy se revela como uno de los fenómenos más importantes de su trayectoria. Se trata de una antología de traducción (Frank, 2001), inédita, elaborada por Rein en sus diferentes fases hacia 1960. El análisis, que debe considerar una serie de particularidades propias del género (Kittel, 1995), parte de la diferenciación teórica entre antologías compiladas por traductores y las realizadas por editores. Según Frank, mientras que en las antologías de editor la función principal se ciñe a la selección de textos que ya circulan en traducción, en las antologías compiladas por traductores, son ellos los responsables de seleccionar, ordenar, traducir y muchas veces comentar los textos del corpus (2001, pp. 13-14). A partir de este marco conceptual, priorizo el abordaje de las principales condiciones históricas externas que permitan comprender cuándo, cómo y en qué circunstancias tuvo lugar el proyecto de Rein (Essman y Frank, 1991, p. 73). 
El carácter inédito y sin catalogar del corpus justifica, por otra parte, el auxilio de herramientas provenientes de la crítica genética en la labor de reconstrucción de una obra en proceso, compuesta por ensayos provisorios y sucesivos. Como resultado parcial, el análisis arroja luz sobre algunas de las intervenciones implicadas en la labor combinada de antologar $\mathrm{y}$ traducir, funciones medulares que afectan la recontextualización de los textos traducidos en la cultura meta (Naaijkens, 2006, p. 513). Por último, es preciso mencionar el vínculo entre la antología y la actividad crítica de Rein en el semanario Marcha entre 1956 y 1960. En ese período aparecen allí una serie de reseñas sobre poesía alemana, cuyos autores y poemas traducidos provienen de la selección realizada para la antología. La serie dialoga con procesos de recepción e importación aún vigentes en el sistema literario vernáculo e introduce, mediante la crítica y el glosado paratextual, un espacio discursivo híbrido que deja ver la reflexividad crítica de Rein respecto de los desafíos que opone la experiencia traductiva.

\section{Hacia un retrato de traductora}

En 1957 Mercedes Rein acaba de recibirse de profesora de Literatura en Enseñanza Secundaria, trabaja en el Departamento de Lingüística de la por entonces Facultad de Humanidades y Ciencias con el lingüista Eugenio Coseriu y colabora como crítica literaria para el semanario Marcha (1939-1974), una de las publicaciones periódicas más comprometidas e influyentes en la vida política e intelectual de Uruguay. Antes, en 1955, había viajado a Alemania con una beca del Deutscher Akademischer Austauschdienst (DAAD) para estudiar durante un año en la Universidad de Hamburgo. Esa experiencia tuvo un gran impacto en su proceso formativo y su posterior proyección en el sistema literario uruguayo, en donde muy pronto se la reconoció como una figura clave en los procesos de transferencia cultural en lengua alemana. ${ }^{2}$ El capital lingüístico acumulado durante su infancia y la relación temprana con la cultura alemana fueron decisivos en el desarrollo de su actividad como crítica literaria. Según le cuenta a Rocca, el crítico uruguayo Emir Rodríguez Monegal, que en 1957 aún comandaba las páginas literarias de Marcha, le habría encargado la reseña de libros, en especial los de lengua alemana. "[E. R. M.] Me encasilló un poco en la literatura alemana, sector que se supone yo conocía mejor. Me hice 'especialista' por imposición ajena" (1993, p. 22). La posición de referente especializada en un área específica de las letras revela la legitimidad de su estatus como agente mediador y constata la permanencia, aun a fines de los años cincuenta, del ambiente favorable (Ortiz, 2012) a las operaciones de importación y transferencia efectuadas por otras figuras de la intelectualidad uruguaya, fundamentalmente a través de revistas culturales.

Entrada la década del sesenta, la amistad y la cercanía académica con Ángel Rama - con quien trabaja como asistente en el Departamento de Literatura Iberoamericana - refuerzan su labor en Marcha. Rama, que entre 1958 y 1968 estuvo a cargo del espacio literario, impulsó la divulgación de lo nacional y latinoamericano sin desatender la producción en lengua extranjera. Durante ese período, las colaboraciones de Rein se multiplican y oscilan entre autores consagrados, como Brecht, Dürrenmatt y Frisch, por un lado, y obras teatrales o puestas en escena producidas en el ámbito

2 Mario Benedetti, uno de los mayores exponentes de la denominada generación del 45 , había sido antes uno de los principales importadores de la literatura en lengua alemana en traducción en las revistas culturales uruguayas. 
de la dramaturgia regional, por el otro. ${ }^{3}$ Además de su creciente afición por el género, la fluctuación de referentes literarios extranjeros y nacionales se explica en buena medida por las fuerzas de continuidad y recambio vigentes en el sistema literario uruguayo de la época, en el que la dimensión política y sociohistórica del continente jugó un papel central. Como es sabido, el triunfo de la revolución cubana profundizó la tensión entre lo nacional y lo cosmopolita, y muchos de los intelectuales de izquierda renovaron su interés por la literatura social producida desde América Latina. En ese contexto, Marcha fue uno de los faros que guio ese viraje. En uno de los ensayos de La generación crítica, Rama describe, entre otras cosas, el nuevo rumbo que afronta la crítica durante su gestión de la página literaria en ese momento:

[...] a mí me correspondió reinsertar la literatura dentro la estructura general de la cultura, lo que fatalmente llevó a un asentamiento en lo histórico y a operar métodos sociológicos que permitieran elaborar la totalidad, reconvertir el crítico al proceso evolutivo de las letras comprometiéndolo en las demandas de una sociedad y situar el interés sobre los escritores de la comunidad latinoamericana, en sustitución de la preocupación por las letras europeas. Fue también la lección del tiempo porque la revolución cubana, la apertura del nuevo marxismo, el desarrollo de las ciencias de la cultura, las urgencias de la hora, marcaban nuevos derroteros (1972, p. 89).

El cambio ideológico es observable también en la reflexión estética de Rein, quien reconoce los desafíos intelectuales emergentes del nuevo escenario sociopolítico:

Había que hacer otras cosas. Claro que los del 45 fueron, son, muy buenos escritores, pero

3 Según el relevamiento para la tesis de maestría de mi autoría "Franz Kafka en Uruguay. Traducciones y recepción crítica", Facultad de Humanidades y Ciencias de la Educación, Universidad de la República, 2014. después la literatura pasó a segundo plano. Sentimos que la ética (y la política) eran más importantes que el arte, y la vida más importante que la estética (Rein en Rocca, 1993, p. 22).

La referencia a la generación del 45 es clave para comprender el diálogo que su obra de traductora entabla con la de sus antecesores. Se sabe que hacia 1940 el grupo de críticos y escritores de la generación del 45 avivó la polémica en torno a la literatura nacional y la extranjera. El núcleo de mayor incidencia, conformado por los integrantes de la revista Número (1949-1955), creía que los procedimientos narrativos foráneos renovarían la anquilosada matriz literaria uruguaya y apostaron así a la difusión crítica y a la importación de autores extranjeros mediante traducciones propias, convencidos "[...] de que sólo a partir de los grandes modelos metropolitanos sería posible hacer una literatura local acorde" (Rocca, 2012, p. 36). Si nos atenemos a la obligada secuencia generacional, Rein pertenece a los intelectuales que vinieron inmediatamente después. Junto con los del 45, formó parte del amplio movimiento cultural que Rama denominó generación crítica (1972) y que involucró a agentes de diversas áreas artísticas y disciplinas del saber que, a partir de la asunción de una nueva conciencia crítica, impulsaron una revisión de los valores estéticos dominantes. En el entendido de que los escritores son los que mejor detectan y revelan estas transformaciones, Rama examina el fenómeno por medio de dos grandes promociones, la crítica (o del 45, según Rodríguez Monegal) y la de la crisis (aquellos que comienzan a publicar a partir del sesenta). Esta última - de la que fue parte Rein- encarnó una transformación acelerada de los presupuestos impulsados por la promoción anterior. Como aquellos, los jóvenes de la crisis ejercieron de forma alternada la actividad crítica y artística, pero postularon la docencia como una función primordial fundada en el diálogo comprometido con la realidad social del país y la región (Rama, 1972, p. 87). También 
Rein vinculó la crítica y la traducción con la investigación académica, tarea que se materializa primero en sus ensayos sobre filosofia del lenguaje y más adelante en sus estudios monográficos sobre autores como Cortázar, Vallejo o Parra. Este desplazamiento de intereses hacia el campo de las letras latinoamericanas se observa asimismo en la dimensión ideológica de su posición traductora, entendida como la forma en que el agente de traducción percibe la tarea traductora e internaliza los discursos que la rodean (Berman, 2009).

Sin duda, el teatro independiente - en tanto instrumento de lucha ideológica y políticaprofundiza su posición crítica acerca del papel histórico y político que las traducciones ocupan en la dinámica de la cultura receptora. Tanto es así que, entre 1959 y 1969, Rein traduce al menos diez títulos de Brecht, Frisch, Dürrenmatt, Weiss, Goethe y Schiller. ${ }^{4}$ Todas ellas son llevadas a escena en salas de Montevideo, mientras que otras, como el Urfaust, aparece en una coedición binacional entre Arca de Montevideo y Galerna de Buenos Aires (1967). También en los sesenta sale por Arca Brecht: ensayos y conversaciones, de Walter Benjamin, volumen que constituye uno de los pilares más significativos del repertorio de traducciones publicadas por entonces. Es claro que la importación y el impacto de estos nuevos paradigmas, sobre todo el del teatro épico de Brecht, deben estudiarse en el marco de los procesos de recepción y producción del sistema teatral uruguayo. No se puede soslayar, por tanto, el hecho de que por

4 De acuerdo al relevamiento realizado como parte de mi investigación de doctorado. La información se encuentra dispersa y para la confección del listado completo de títulos y autores traducidos he consultado el registro de la Biblioteca Nacional de Uruguay, AGADU y un documento personal hallado en el archivo de la escritora. La información sobre Brecht fue cotejada además con la cronología de teatro dirigida por Roger Mirza para el período 1959-1972 (2018). la misma época otros agentes de traducción, en su mayoría escritores y críticos de la promoción del 45 , traducían de otras lenguas para el circuito teatral independiente, como es el caso de Ida Vitale, Idea Vilariño o, en menor medida, Emir Rodríguez Monegal (Mirza, 2018). ${ }^{5}$ En lengua alemana, la labor de dos autores de origen alemán, como Luis Novas Terra (Ludwig Neuländer) y Federico Wolff, amplía el repertorio local con traducciones de Büchner y Weiss, entre otros (Mirza, 2018).

Un modo de rescatar y comprender la apropiación discursiva de Brecht por parte de Rein es a través de los relatos personales y los de otros intelectuales contemporáneos que posibilitan "observar de cerca el medio particular y generalmente determinante en el que ha germinado una traducción" (Delisle, 2010, p. 15). Así, la autora recuerda en diálogo con Rocca las circunstancias que la guiaron a Brecht y que se remontan, una vez más, a su labor como crítica:

En esas reseñas de Marcha sobre escritores alemanes, a veces tenía que ilustrar mis comentarios con alguna traducción. A raíz de eso Ugo Ulive, que era de El Galpón y compañero mío del IPA, me llamó para que hiciera la adaptación del Círculo de tiza caucasiano, de Brecht (1993, p. 22).

El episodio también es narrado por el propio Ulive, quien en Memorias de teatro y cine (2007), recrea el encuentro personal y la posterior incorporación de Rein al equipo de trabajo como traductora y revisora de las canciones brechtianas, textos que traducía seguramente para la antología. El relato de Ulive jerarquiza la función de la figura del traductor en el

5 Sobre la actividad traductora de Vilariño y Rodríguez Monegal en la revista Número puede verse el estudio de Julia Ortiz sobre la traducción conjunta de Crimen en la catedral, de T. S. Eliot (Ortiz, 2012). 
circuito intelectual de entonces y ayuda a recomponer el tejido de conexiones, encuentros y amistades que facilitaron la circulación de Brecht en Uruguay. ${ }^{6}$

En eso estaba una vez cuando se acercó una muchacha flaca y tímida y me preguntó qué estaba haciendo el Galpón. [...] Noches más tarde conversamos nuevamente y dijo algo que despertó mi interés: estaba dedicada a traducir unas canciones o poemas de Brecht, no recuerdo exactamente. Logré que viniese a nuestra sede y cuando lo hizo se la presenté a Atahualpa [del Cioppo], que simpatizó con ella de inmediato. [...] Cuenta el folclore interno galponero [...] que en una de las reuniones en las que se revisaba el texto de la obra tropezaron con una palabra obscena [...] Al parecer los traductores argentinos habían optado por una versión bastante tibia. Atahualpa pensó un momento y luego, silenciosamente, escribió en un trozo de papel una palabrota y se lo pasó a Mercedes, a quien todos ya llamaban Mecha. Ella lo leyó, miró de nuevo el texto original y escribió en el mismo papel otra grosería de muy grueso calibre. Era natural (y también divertido) que dos seres tan tímidos y respetuosos como ellos no se atreviesen a pronunciar en voz alta vocablos tan violentos (Ulive, 2007, pp. 125-126).

En 1974, la dictadura interpuso una pausa obligada a todas las actividades de Rein. La edición completa de Zoologismos — su primer volumen de cuentos publicado en 1967- es requisada del mercado, ella es destituida de su trabajo docente y el semanario Marcha es clausurado. Ese período de incertidumbre, reclusión y profundas restricciones impacta de un modo impredecible su trayectoria intelectual. Ella misma reconoce,

6 El trabajo de Rein en torno al teatro de Brecht también fue reconocido fuera de Uruguay, como lo atestigua la invitación al congreso "Brecht-Dialog" del Instituto Internacional del Teatro, celebrado en Berlín en 1968, según documento hallado entre los papeles personales de la traductora. no sin cierto obligado optimismo, las secuelas positivas de ese período en el desarrollo su proyecto novelístico: "En 1975 tuve que jubilarme, me jubilaron, y así pude escribir novelas: no tenía un horario que cumplir, pude alcanzar una continuidad en el esfuerzo" (Rein en Rocca, 1993, p. 22). ${ }^{7}$ Además, en entrevista con Ruffinelli, la autora comenta que la traducción fue, junto con una jubilación prematura que obtuvo por enfermedad, uno de los recursos clave que le permitió subsistir durante en esos años: "Traducía e hice apuntes de estudio para Casa del estudiante; pagaban muy poco. Y algunas traducciones para el teatro. Pero llegó un momento en que incluso en el teatro el clima se empezó a poner más espeso y entonces paré [...]" (Rein en Ruffinelli, 2010, p. 306).

\section{Poetas alemanes en traducción. La serie de Marcha}

Como se menciona en la introducción, las primeras traducciones de Rein en Marcha comienzan en 1956 y se extienden hasta 1960 con al menos tres reseñas sobre poetas en lengua alemana. ${ }^{8}$ En esas reseñas, Rein combina el comentario crítico con traducciones parciales que también comenta y, en ocasiones, las confronta con el original. ${ }^{9}$ De esta forma, tan-

7 Con la restauración de la democracia, aparecen por la editorial Arca los libros Casa vacía (1984) y Bocas de Tormenta (1987), títulos que más tarde ella misma reunirá en el volumen Marea Negra (1996).

8 En su primera reseña, "Bertolt Brecht y su Madre Coraje” (1956), Rein aborda la obra dramática de Brecht en el año de su muerte e incluye un breve comentario a la traducción de Madre Coraje y sus hijos publicada por Ediciones Losange de Buenos Aires en 1954.

9 Los poetas reseñados, comentados y traducidos en Marcha son Rainer Maria Rilke (1957) y Bertolt Brecht (1959). En un artículo panorámico, "Poesía alemana hoy" (1960), Rein presenta un recorrido por las distintas vertientes y representantes de la poesía de posguerra (Grass, Rühmkorf, Riegel, Bachmann, Enzensberger, Holthusen) y ofrece un poema de Hans Egon Holthusen 
to el poema traducido como el glosado que lo sostiene detienen la atención del lector en operaciones específicas de la traducción de poesía, por lo general, sobre las concesiones léxicas derivadas de la restitución sonora en la lengua meta. El artículo que mejor ilustra este fenómeno es el de Rainer Maria Rilke y la traducción parcial del poema Requiem für eine Freundin, en el que la reiteración de los desafíos traductivos de ciertos pasajes ocupa un espacio tan relevante como el análisis interpretativo del texto poético en sí. La primera traducción del poema fue compuesta en 1955 durante "la soledad de estudiante becada en Hamburgo" (Rein, 2007a). La segunda se publica parcialmente y con correcciones en Marcha, en 1957, e incluye transcripciones textuales del original. En la introducción, Rein menciona entre otras cosas la relevancia de la restitución rítmica, puesto que "la mera versión de ideas e imágenes quedaría muy lejos de la intención del poeta" (1957, p. 21). En la versión de Hamburgo, agregaba: "[...] Las palabras obviamente se pierden. La versión literal sería la más alejada de la fidelidad conceptual y poética [...]" (2007a, p. 20). Las palabras liminares y el glosado que hilvanan los fragmentos traducidos configuran de forma progresiva un espacio de saber específico que puede vincularse con 1o que Patricia Willson (2019) denomina translaturire, esto es, un orden del saber que solo el traductor puede elaborar y sostener, y que revela su querer-traducir.

La presencia de los poetas traducidos en Marcha es llamativa en varios sentidos. Para el sistema literario uruguayo y su proceso de apertura a las literaturas del mundo, el papel del semanario y el de otras publicaciones de corte cosmopolita, es capital. Sin embargo,

traducido de forma íntegra. En 1958 aparece además un artículo sobre la obra dramática y narrativa de Wolfgang Borchert. hacia fines de los cincuenta el auge de las revistas del 45 comienza a declinar y solo unas pocas mantienen, en dosis dispares, artículos, reseñas o traducciones del alemán. A la vez, en el campo de la poesía vernácula un número considerable de poetas, mayormente de la generación crítica, publica sus propios libros y otros alcanzan estado público a través de nuevas revistas especializadas, como Aqui Poesía, que promueve a los nuevos autores y da a conocer la poesía militante nacional y extranjera (Rama, 1972, p. 189). En este contexto, la introducción de Brecht por medio de Marcha y Aquí Poesía representa un gesto con el que Rein habría apostado a ampliar los recursos poéticos vigentes en un momento de transformación y rescate de formas como la de la canción. ${ }^{10}$ No es casual, por otra parte, que en su artículo de Marcha (1959) sobre la poesía de Brecht, Rein enfatice la medida tradicional de la balada y su sencillez popular como dos rasgos centrales del lírico social, características que ilustra mediante la traducción parcial de al menos ocho poemas (1959, pp. 22-23). La relevancia de la poesía alemana traducida en publicaciones periódicas posteriores a 1955 puede leerse, siguiendo el caso de Marcha, como una forma de apropiación de ciertas poéticas por parte de escritores y poetas del sistema literario local, ${ }^{11}$ como ocurrió con la traducción sistemática de Rilke a partir de los cuarenta (Pagni, 2019; Rama, 1972) y más adelante con Brecht, aunque su caso se caracterizó por la preeminencia de la figura del dramaturgo sobre la del poeta (García, 2012; Brooker, 2017). Por último,

10 En el número dos de Aqui poesía (1962) aparece, entre textos de Juan Gelman y Alfredo Zitarrosa, "Del pobre B. B." de Brecht en traducción de Rein (Brecht, 1962).

11 Me refiero aquí a la traducción de poetas en lengua alemana, pero el fenómeno puede extenderse a la presencia de otros poetas en traducción, como el caso del francés Raymond Quenau y las traducciones de Idea Vilariño para la revista Número (1955). 
resta aclarar que el hallazgo en el archivo de la escritora de los borradores de la antología de traducción fue clave para comprender el origen de las reseñas en prensa, puesto que los nombres y los poemas publicados resultaron ser solo una muestra de un proyecto de traducción de poesía más amplio que carece de antecedentes locales conocidos.

\section{Poesía alemana. 1900-1960: una antología de traducción inédita}

Por tratarse de la primera aproximación a un corpus inédito y sin catalogar, conviene comenzar por describir e interpretar las marcas de su cronología y analizar luego, de forma exploratoria, algunas de las intervenciones textuales que se producen y reformulan de acuerdo a las variaciones históricas y culturales del contexto. El ordenamiento parcial de los materiales arrojó como resultado la identificación de tres grandes grupos de borradores en fase redaccional con fluctuaciones en diversas dimensiones. Mi análisis se concentra en aspectos relacionados con la autoría, el formato y los propósitos del proyecto, así como en las variantes textuales en el corpus y parte de los paratextos, entendidos aquí como los peritextos que median entre el lector y la obra y que garantizan su recepción (Genette, 2001). Vale aclarar, que aun tratándose de una obra sin editar, los paratextos funcionan en la estructura de la antología como un discurso auxiliar al servicio de un texto (Genette, 2001, p. 16) que fue concebido para hacerse público.

La primera referencia temporal a la antología fue hallada en las copias de los currículums de Rein, que la ubica bajo el apartado de "Inéditos" y establece 1960 como el año en el que gana el Premio municipal (de Montevideo) en la categoría Ensayo ${ }^{12}$ con el título "Poesía

12 El propósito central del premio consistía en favorecer la publicación de obras en un medio editorial in- alemana del siglo xx". Sin embargo, el título alterna en los borradores entre "Ensayo sobre poesía alemana contemporánea", "Poesía alemana. 1900-1960" y el que figura en los currículums, cuyo correspondiente legajo aún no ha sido identificado. Esta oscilación del aparato titular es, como se verá, la evidencia documentada de otras tantas intervenciones que afectan su desarrollo compositivo a lo largo de varios años. En primer lugar, la anotación a mano en el espacio gráfico de la portadilla del último borrador, cuya descripción se incluye hacia el final de este artículo, permite situarla en el marco de la labor académica de Rein, al tiempo que revela interrogantes acerca de la posible intervención de otros agentes en su proceso de creación. Si, como consta allí, el proyecto "fue realizado [...] bajo la dirección y con el asesoramiento del Profesor Eugenio Coseriu, jefe del Departamento" (1958), cabría preguntarse por el grado de participación del profesor en alguna de sus fases. Aunque no es fácil de establecer, pueden formularse algunas hipótesis provisorias al respecto. ${ }^{13}$ En principio y con base en todo lo expuesto, no parece desacertado afirmar que la idea comienza por la propia Rein. Su beca en Alemania y luego su tarea docente en el Departamento de Lingüística habrían favorecido el desarrollo del proyecto. Es de destacar

cipiente y vulnerado por la crisis económica de 1955, según consta en la resolución sobre el concurso recogida en el Registro Oficial Intendencia Municipal de Montevideo (1958, p. 185). En 1960 el premio para la categoría Ensayo fue compartido con otros cuatro autores que, como Rein, eran docentes del Instituto Profesores Artigas y de la Facultad de Humanidades y Ciencias. Los ganadores fueron Pedro Leandro Ipuche, Mario Sambarino, Roberto Ibáñez y José Pedro Rona. El jurado estuvo integrado, entre otros, por Carlos Real de Azúa y Emir Rodríguez Monegal.

13 De acuerdo a Johannes Kabatek, responsable del Coseriu-Archiv alojado en la Universidad de Tübingen, no se han encontrado hasta el momento documentos asociados al proyecto de Rein. (Intercambio por correo electrónico en enero de 2020). 
que, en ese departamento, fundado por el propio Coseriu en 1951, la traducción es objeto de reflexión y una práctica frecuente que responde, en parte, a la necesidad de bibliografía actualizada en español para el dictado de cursos (Kabatek y Murguía, 1997). Además, la revista del departamento publica traducciones, investigaciones y ensayos tanto de su director como de los colaboradores. Sin embargo, en su conversación con Kabatek y Murguía, Coseriu solo menciona a Rein a propósito de su estudio sobre Ernst Cassirer (1997, p. 88) ${ }^{14}$ Es posible, no obstante, que la haya asesorado al comienzo y que luego, a medida que Rein se involucraba con Marcha, la autora haya ampliado el formato y los objetivos del proyecto más allá del ámbito académico.

En efecto, una de las particularidades de la versión titulada "Ensayo sobre poesía alemana contemporánea" es su carácter monolingüe. Los folios dactiloscritos en tinta azul se encuentran engrampados, algunos de ellos fueron recortados y otros aparecen duplicados en hojas sueltas. La introducción fue corregida a mano en varios momentos y las "Notas a los poemas" fueron ubicadas a pie de página. La versión no está fechada, pero comparada con las otras es más breve - los poemas figuran solo en traducción - y el corpus de poetas es más reducido. La única referencia directa a la fecha de creación se consigna en otro borrador en apariencia posterior. Allí aparece el año 1962 por encima de un 1961 tachado a mano, por lo que puede inferirse que después de 1960 -el primer mojón temporal documentado en el currículum - Rein continúa revisando y ampliando lo que habría sido en primera instancia un ensayo, para convertirlo de forma progresiva en una amplia selección bilingüe, posiblemente

14 Ernst Cassirery la filosofía del lenguaje de Mercedes Rein (1959) fue el primer ensayo publicado en el marco de su trabajo docente en el Departamento de Lingüística. con el propósito de publicarla en formato libro. En este punto no es difícil adivinar la intervención de Rama que, como se ha expuesto, propicia la divulgación de lo que serían adelantos en la página literaria de Marcha y en un número de 1960 menciona, incluso, la inminente salida de la antología por una editorial porteña, cuyo nombre no menciona (1960, p. 21). El hecho es significativo porque confirma que, en efecto, Rein pensaba publicar, auque fuera de Uruguay. Se desconocen hasta el momento las razones que lo impidieron, pero está claro que el fenómeno debe articularse con lo que se producía en materia de poesía alemana en Argentina, en donde recién "[...] a mediados de los sesenta había comenzado a percibirse que la literatura alemana contemporánea brillaba por su ausencia en los circuitos literarios argentinos y rioplatenses" (Pagni, 2019, p. 17). Si se lo considera en el marco del tránsito editorial entre Uruguay y Argentina, podría pensarse que los números especiales de Sur dedicados a las literaturas extranjeras - presentados mayormente en ediciones bilingües - pudieron servir de referencia a Rein en la ampliación de su proyecto (Schoor, 2017).

Existe un tercer legajo que, por sus características compositivas, he denominado último borrador. ${ }^{15}$ Ahora bajo el título "Poesía alemana. 1900-1960”, Rein reúne una selección de 67 poemas - en lengua original y en traducciónde 36 autores presentados de forma cronológica. Esta versión consta de 175 páginas dactiloscritas engrampadas a una carpeta perteneciente a la papelería de la "Universidad de la República. Facultad de Humanidades y Ciencias", según consta en la carátula. No hay mención a fechas, pero existen otras huellas materiales

$15 \mathrm{Al}$ respecto me interesa puntualizar que la fijación de un borrador final funciona aquí de forma provisional y no descarta el tratamiento de los otros documentos como insumo complementario. 
que la señalan como una posible última versión, sobre todo por las diferentes campañas e instrumentos de escritura utilizados en las tachaduras, agregados y supresiones en todo el volumen (Grésillon, 2005). También aquí se observan folios recortados y otros agregados o duplicados; reescrituras en los paratextos y en los textos traducidos (en el sentido aquí de correcciones, de acuerdo a la terminología de la genética textual); así como modificaciones en el índice de poetas y poemas. Sobre esto hay al menos dos aspectos que llaman la atención, pero cuyo tratamiento queda relegado a próximos trabajos. Por un lado, la cantidad de poemas seleccionados por autor es dispar. Destacan los consagrados como Stefan Georg, Hugo von Hofmannstahl, Rainer Maria Rilke, Bertolt Brecht y Gottfried Benn con cuatro o cinco poemas y, por otro lado, al menos veinte poetas figuran con un solo poema traducido. En cuanto a las modificaciones en el corpus, dos poetas - Günther Deicke y Christa Reinigfueron suprimidos por medio de tachaduras, mientras que Johannes Becher (poeta de la República Democrática Alemana) y su poema "Andrajo" fueron agregados a mano en otro momento. Capítulo aparte merece el análisis de la escritura en proceso de los textos traducidos, tema que se manifiesta por medio de una multiplicidad de variantes y que presento parcialmente en un artículo que se encuentra en prensa. ${ }^{16}$

El aparato paratextual conserva el mismo orden en los tres legajos, pero varía en alguno de sus componentes. Los treinta folios de la introducción, en los que se explicitan los propósitos y se describen las tendencias estéticas

16 El artículo será publicado en Lenguas, literaturas extranjeras y traducción literaria, volumen dos de la serie Estudios de Lenguas (CELex, Facultad de Humanidades y Ciencias de la Educación, Udelar) que dirige Laura Masello. y los autores más representativos de la poesía en lengua alemana entre 1900 y 1960, fueron corregidos y reescritos en un gran número de pasajes y un segmento fue adaptado para el artículo "Poesía alemana hoy", publicado en Marcha (1960). Como los otros, este legajo también ofrece reseñas biobibliográficas de cada uno de los antologados y un aparato de "Notas a los poemas", que se ubica en anexo al final del volumen. Vale la pena mencionar, a modo de adelanto, que el gran número de intervenciones en las notas - incluso con relación a las de los otros legajos - posibilita una aproximación interpretativa al método traductor de Rein. Al igual que el glosado que rodea las traducciones de Marcha, la nota opera como un espacio enunciativo que visibiliza aspectos específicos de la traducción de poesía. Sin embargo, en más de la mitad de ellas (son 52 en total) Rein ofrece soluciones literales para versos o partes de estrofas que traduce en el cuerpo de los textos con mayor autonomía respecto de la lengua fuente. Descontando la posible voluntad pedagógica de las notas - en la que subyace, además, una idea de lector-, este fenómeno, que afecta tanto al método como a la reflexión metadiscursiva de la traductora, puede vincularse con los testimonios recogidos por Ruffinelli en una encuesta publicada en Marcha, en 1973. ${ }^{17}$ Allí Rein reconoce como la cualidad fundamental del traductor su "doble capacidad mimética y expresiva, comparable a la doble actividad imitadora y creadora, ceñida a un texto y libre a la vez, que debe desarrollar un actor" (en Rufinelli, 1973, p. 30) (el marcado es mío). Aunque la analogía es una representación metatraductiva frecuente, resuena en ella una concepción de la traducción literaria consonante con las teorizaciones tempranas de Levý (2011), quien la define como una práctica intermedia entre un arte de tipo reproductivo y otro de creación

17 En esa encuesta participan además Ida Vitale, Idea Vilariño y Pedro Scarón, el traductor de Marx para Siglo xxI, según Ruffinelli (1973, p. 30). 
(pp. 57-58). La coexistencia de la literalidad paratextual con el empleo de recursos creativos en la lengua meta instaura una tensión dentro de la propia antología entre dos formas de traducir que, combinadas, proponen un contrapunto entre el ocultamiento y la visibilización del estatus creativo de las estrategias traductoras. El planteo de Levý en torno a los métodos ilusionistas y antiilusionistas de traducir (pp. 19-20), así como el de otros autores contemporáneos, ofrece una plataforma interpretativa a través de la cual indagar, a modo de hipótesis de trabajo, en una posible relación de reciprocidad y contrapunto entre estas dos tendencias.

\section{Cierre provisional}

En el presente artículo se ha intentado consignar, ante todo, la obra de traductora de Mercedes Rein, una de las figuras intelectuales más polifacéticas del sistema literario uruguayo. En el marco de los procesos de importación y recepción de las letras en lengua alemana, la recomposición histórica de su trayectoria revela una obra heterogénea y de gran magnitud que en muchas de sus fases permanece sin explorar. El análisis, que considera algunas de las restricciones sociales, culturales y económicas que determinaron su labor dentro del campo local (Sapiro, 2014), revela las fluctuaciones de su posición traductiva en torno a dos grandes proyectos - el de poesía y teatro- que emergen hacia 1959, año clave para la región. A diferencia de las traducciones de teatro producidas de forma programática durante los años sesenta, el proyecto traductivo en torno a la poesía es parte de una práctica generacional con características propias.

Vinculada en sus comienzos al gesto importador protagonizado por los escritores de la generación del 45, las traducciones de Rein en prensa cultural constituyen un fenómeno epigonal y original a la vez. Como gesto asociado a la recepción de literatura extranjera, la serie de poesía alemana publicada en Marcha no representaría un hecho singular, más allá de su carácter asincrónico respecto del progresivo perfil político de algunas de las revistas de mediados de los cincuenta. Sin embargo, hay al menos dos elementos infrecuentes que la distinguen. Por un lado, la configuración de un espacio de enunciación híbrido, producto de la interacción entre crítica literaria y práctica traductora, que estatuye una forma reflexiva y democratizadora de concebir el acto traductivo, tanto en términos de legibilidad como desde el punto de vista creativo (Willson, 2019, p. 27). Por otro lado, la importación de operaciones y repertorios poéticos foráneos estaría relacionada con la reelaboración de formas heredadas y la búsqueda experimental a cargo de los poetas críticos que comienzan a publicar por esa época.

El rescate de la antología de traducción de Rein amplifica la posibilidad de investigar sobre la dimensión histórica y cultural de la actividad traductiva y su vínculo con otras prácticas colindantes como la crítica. Por otra parte, aunque el carácter inédito del material complejiza el trabajo interpretativo y metodológico, habilita a la vez el acceso a las múltiples intervenciones implicadas en la confección de este tipo de antologías. La descripción material de la cronología de los tres legajos de borradores es el resultado de una aproximación parcial que aún conserva vacíos o eslabones perdidos (Grésillon, 2005). La posible publicación de la antología es un hecho significativo que se debe rastrear de forma articulada con el estudio de la circulación del libro en el mercado editorial de Uruguay y Argentina de principios de los sesenta. El valor de la recuperación documental de la obra radica precisamente en la posibilidad de indagar en estos fenómenos y en las circunstancias que permitieron, en un principo, su gestación y desarrollo. En este sentido, 
reivindico la operatividad de la crítica genética en la recuperación del corpus y por posibilitar la sistematización de las operaciones de escritura y reescritura presentes en los borradores. A través del análisis de tachaduras, arrepentimientos y sobreescrituras, es posible acceder a las particularidades específicas de la escritura de traducción en proceso, es decir, al modo en que las estrategias traductoras se buscan, se ensayan y se descartan en los distintos tramos de una traducción. La investigación en curso proyecta profundizar en el estudio de las estrategias que subyacen al método traductor de Rein y que, en la antología, aparece tensionado por la dinámica contrapuntística impuesta por la literalidad de las notas.

\section{Fuentes}

Archivo Mercedes Rein. Academia Nacional de Letras, Ministerio de Educación y Cultura. [Manuscritos y dactiloscritos inéditos, documentos personales, correspondencia].

\section{Referencias}

Actas del Concurso Literario Municipal (1958). Resolución 45.464 sobre el Concurso Literario Municipal (llamado a obras 1957). En Registro Oficial Intendencia Municipal de Montevideo, tomo xv, pp. 185-187, Montevideo.

Berman, A. (2009). Toward a translation criticism: John Donne. (François Massardier-Kenney, Trad.). The Kent State University Press.

Brecht, B. (1962). Del pobre B. B. (Mercedes Rein, Trad.). Aquí poesía, 2, 17-18.

Brooker, P. (2017). Bertolt Brecht: Dialectics, poetry, politics. Routledge.

Delisle, J. (2018). Retratos de traductores y traductoras. (Grupo de Investigación en Traductología, Trad.). Mutatis Mutandis Ebooks. [PDF]. https://revistas.udea.edu. co/index.php/mutatismutandis/article/ view/336769/20792107

Essman, H. y Frank, A. P. (1991). Translation anthologies: An invitation to the curious and a case of study. Target, 3(1), 65-90. https://doi.org/10.1075/target.3.1.05ess

Frank, A. P. (2001). Translation anthologies. En M. Baker y K. Malmkjaer (Eds.), Routledge encyclopedia of translation studies (pp. 13-17). Routledge.

García, L. (2012). Brecht y América Latina. Modelos de refuncionalización. A Contra corriente, 2, 65-100.

Genette, G. (2001). Umbrales (Susana Lage, Trad.). Siglo XXI.

Grésillon, A. (2005). Glosario de crítica genética (Aurore Baltasar, Trad.). En F. Colla (Coord.), Archivos. Cómo editar la literatura latinoamericana del siglo XX (pp. 289-296). CRLA.

Kabatek, J. y Murguía, A. (1997). Die Sachen Sagen, wie Sie Sind... Eugenio Coseriu im Gespräch. Gunter Narr Verlag.

Kittel, H. (1995). Anthologies of literature in translation: The Göttingen research project. En H. Kittel (Ed.), International anthologies of literature in translation (pp. 271278). Erich Schmidt.

Levý, J. (2011). The art of translation (Patrick Corness, Trad.). John Benjamins. https:// doi.org/10.1075/btl.97

Mirza, R. (Dir.). (2018). Cronología de estrenos teatrales en Uruguay, 1959-1972. Montevideo. Recuperado de http://anaforas.fic. edu.uy/jspui/handle/123456789/40512 [Último acceso: 15-5-2020].

Naaijkens, T. (2006). The world of poetry: Anthologies of translated poetry as a subject of study. Neophilologus, 90, 509-520. https://doi.org/10.1007/s11061-006-0004-y

Ortiz, J. (2012). Prácticas traductoras en el Río de la Plata. En P. Rocca (Ed.), Revistas culturales del Río de la Plata. Diálogos y tensiones (1945-1960). csic/UdelaR, 85-88. 
Pagni, A. (2019). Traducir y antologar poesía: las circunstancias de Poesía alemana de hoy (1945-1966). Una antología a cargo de Klaus Dieter Vervuert. En M. de la Campa, R. Fine, A. González, C. Strosetzki (Eds.), El libro y sus circunstancias. In $\mathrm{Me}$ moriam Klaus D. Vervuert (pp. 533-567). Iberoamericana/Vervuert. https://doi. org/10.31819/9783964568588-031

Quenau, R. (1955). Sonetos (Idea Vilariño, Trad.). Número, 6(27), 122-123. Recuperado de http://anaforas.fic.edu.uy/jspui/ handle/123456789/120 [Último acceso: 29-05-2020].

Rama, Á. (1960). Poesía alemana. Marcha, 1.039, 21.

Rama. Á. (1972). La generación crítica (19391969). Arca.

Rein, M. (s/f). Poesía alemana. 1900-1960. Antología bilingüe, inédita. Archivo Mercedes Rein. Academia Nacional de Letras.

Rein, M. (1956). Bertolt Brecht y su Madre Coraje. Marcha, 828, 22-23.

Rein, M. (1957). Requiem para una amiga. Un poema de Rainer Maria Rilke. Marcha, 884, 22-23.Rein, M. (1959). Aproximación a la poesía lírica de Bertolt Brecht. Marcha, 970, 22-23.

Rein, M. (1959). Ernst Cassirer y la filosofia del lenguaje. FHC.
Rein, M. (1960). Poesía alemana hoy. Variaciones sobre tiempo y muerte (Hans Egon Holthusen, 1913). Marcha, 1.035, 22.

Rein, M. (1967). Zoologismos. Arca.

Rein, M. (2007a.). Requiem para una amiga. Revista de la Academia Nacional de Letras, 2, 20-30.

Rein, M. (2007b.). [Autobiografía]. Revista de la Academia Nacional de Letras, 2, 31-44.

Rocca, P. (Ed.) (2012). Revistas culturales del Río de la Plata. Diálogos y tensiones (19451960). csic/U de la R.

Rocca, P. (1993). La traducción de la experiencia interior. Brecha, 22-23.

Ruffinelli, J. (1973). La tarea secreta del traductor. Marcha, 1.650, pp. 30-31.

Ruffinelli, J. (2010). Mercedes Rein: contemplar el mundo con distancia. Nuevo Texto Crítico, 23(45-46), 297-309. https://doi. org/10.1353/ntc.2010.0009

Sapiro, G. (2014). Normas de traducción y restricciones sociales (Melina Blostein, Trad.). Residencia de Traducción del IESLV "J. R. Fernández", mimeo.

Schoor, U. (2017). Letras alemanas contemporáneas en Sur: hacer pie en América Latina. Lenguas Vivas, 13, 97-115.

Ulive, U. (2007). Memorias de teatro y cine. Trilce. Willson, P. (2019). Página impar. Textos sobre la traducción en Argentina: conceptos, historia, figuras. Ethos.

Cómo citar este artículo: Hornos-Weisz, L. (2020). Mercedes Rein y su obra de traductora. Aproximación a una antología de traducción inédita. Mutatis Mutandis. Revista Latinoamericana de Traducción, 13(2), 319-332. https://doi.org/10.17533/udea.mut.v13n2a06 